\title{
Durability research of C60 High-strength Mass Concrete Foundation Slab
}

\author{
Wen Yang ${ }^{1, a}$, Hanyang Huang ${ }^{1, b}$, Erbo Pang ${ }^{1, c}$, Lei Qu ${ }^{1, d}$ \\ ${ }^{1}$ China Construction Ready Mixed Concrete Co. Ltd, Wuhan 430205, China
}

Keywords: durability; Impermeability; Shrinkage; Slab cracking test

Abstract. Combined with Wuhan Yongqing commercial zone slab requirements, the engineering application concrete mix ratio is determined by testing the durability and mixing optimization, finally realizing one-time continuous pouring $25000 \mathrm{~m}^{3}$ C60 High-strength Mass Concrete Foundation Slab and ensuring the engineering quality of the foundation slab concrete.

\section{Introduction}

Yongqing Commercial Zone is located in Hankou, which is the second tallest building developed by Wuhan now, the A1 block tower height will be 468m, C60 High-strength Mass Concrete Foundation Slab dimensions is $86 \mathrm{~m} * 51 \mathrm{~m}$, elevator shaft down to $11.7 \mathrm{~m}$, an average thickness is about $4.5 \mathrm{~m}$, we need to pour $25000 \mathrm{~m}^{3}$ C60 High-strength Mass Concrete continuously at one-time, high strength, large cast party, and construct in the hot season are the biggest challenge for this project. Therefore, the durability of the project pre-assessment has a certain significance of improving the design level and quality of construction projects ${ }^{[1]}$.

In the early implementation of the project, our group did a lot of thermal calculation, considering of the performance of Foundation Slab Concrete, the compressive strength and hydration heat, we choose three kinds of mixing ratio to test the concrete durability, which is shown in Table 1-1.

Table 1-1 Engineering Application Mix Ratio $/\left(\mathrm{kg} / \mathrm{m}^{3}\right)$

\begin{tabular}{ccccccccc}
\hline mixing & cementitious material & Cement & Fly ash & slag & Sand & Stone & water & Superplasticizers \\
\hline SP-1 & 480 & 210 & 160 & 110 & 740 & 1060 & 158 & 5.8 \\
SP-2 & 450 & 280 & 100 & 70 & 760 & 1060 & 152 & 5.5 \\
SP-3 & 450 & 250 & 150 & 50 & 760 & 1060 & 150 & 5.4 \\
\hline
\end{tabular}

\section{Test methods}

Resistance to chloride ion penetration test. concrete resistance to chloride ion permeability is determined by the ASTM C1202, test age is 56d and 90d, we place the water-saturated concrete specimens at both ends into $3.0 \mathrm{wt} \%$ Sodium chloride and $0.3 \mathrm{~N}$ sodium hydroxide solution, the total power of concrete specimens is measured at $60 \mathrm{~V}$ electric field for $6 \mathrm{~h}$, resistance to chloride ion penetration is determined by the level of electricity through concrete.

Shrinkage test. The autogenous shrinkage of concrete is tested by Non-contact method and concrete drying shrinkage is tested by contact method according to GB/T 50082-2009 "ordinary concrete long-term performance and durability test method standards"

Slab cracking test. Cracking grade evaluation of the three Mixing is tested by GB/T 50082-2009 "ordinary concrete long-term performance and durability test method standards" and CCES01-2004 "Durability of Concrete Structures Design and Construction Guide" .Specific evaluation criterias are as follows:

(1) Only slender cracks

(2) The average crack area is less than $19 \mathrm{~mm}^{2} /$ root

(3) the number of cracks per unit is less than 10

(4) total Cracking area is less than $100 \mathrm{~mm}^{2}$ Per square meter 
There are five levels based on the above four criteria:

I: All meet the above four conditions;

II: meet three conditions;

III: meet two conditions;

IV: meet one condition;

$\mathrm{V}$ : meet none of the conditions.

\section{Experimental Research on Durability}

Impermeability. Concrete durability research is inseparable with the permeability of concrete, Concrete permeability refers to gas, liquid or ions penetration, diffusion or migration capability in the concrete when under pressure, the chemical potential or electric field. In the reinforced concrete structure, if chloride ions penetrate into the concrete, and when it reaches a certain limit cumulative content, it will rust the steel inside, the deterioration of reinforced concrete structures is known as salt damage. Therefore, the key to obtaining high concrete durability and long life is to improve the impermeability of concrete ${ }^{[2]}$.

We selected the electric flux test method to assess the anti- chloride ion permeability grade of the three mixing concrete samples .The test results are shown in Table 3-1.

Table 3-1 resistance to chloride ion penetration test

\begin{tabular}{cccc}
\hline mixing & 56d (C) & 90d (C) & Chloride ion permeability \\
\hline SP-1 & 531 & 378 & low \\
SP-2 & 485 & 331 & low \\
SP-3 & 462 & 302 & low \\
\hline
\end{tabular}

Shrinkage test.Concrete is a heterogeneity composite material, The elastic modulus of aggregate and cement paste are extremely different, microscopic and macroscopic appearance of concrete cracking is caused by tensile stress at concrete early shrinkage, which exceeds the limits of the matrix tensile stress, thereby affecting durability. Early volume changes affect the formation of the final volume of concrete and cracks, they are all important to concrete durability ${ }^{[3-5]}$.

The autogenous shrinkage and drying shrinkage test results of SP-1, SP-2 and SP-3 are shown in Figure 3-1 and Figure 3-2.

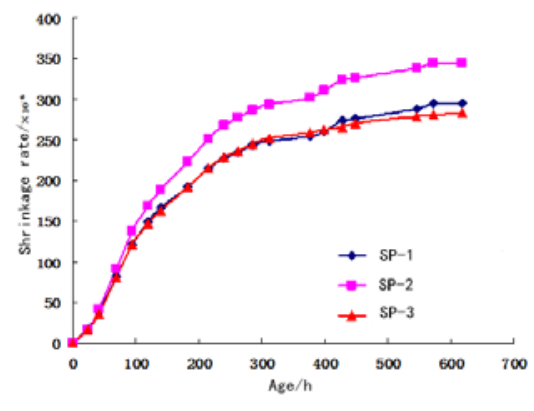

Fig. 3-1 drying shrinkage test

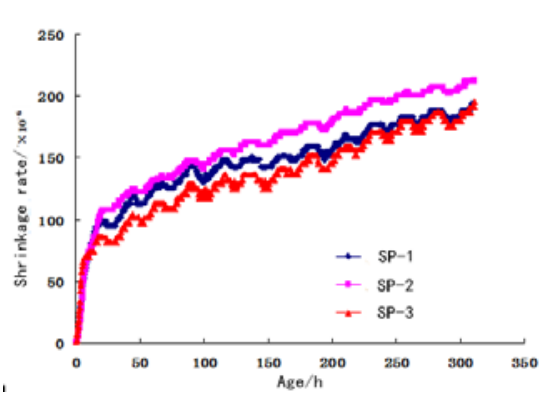

Fig. 3-2 autogenous shrinkage test

The data from Figure 3-1 and Figure 3-2 indicates:

(1) Shrinkage occurs mainly in the $7 \mathrm{~d}$ age,the self shrinkage curve tangent slope decreases obviously after 7 days.

(2) $28 d$ drying shrinkage rate of SP-1, SP-2, SP-3 are $2.9 \times 10^{-4} 、 3.5 \times 10^{-4}$ and $2.8 \times 10^{-4}$, autogenous shrinkage rate are $1.9 \times 10^{-4} 、 2.1 \times 10^{-4}$ and $1.9 \times 10^{-4}$.

(3) SP-2 mixing has a maximum dry shrinkage and self shrinkage, which caused by big cement dosage.

Plate cracking test. High strength concrete has higher brittleness and lower tensile ability, concrete structure is easy to produce cracks in the surface even through cracks under the internal 
and external constraint. In the reinforced concrete structure, Concrete can not deforme freely by surrounding reinforced constraints, it is easy to produce cracks, the crack test results are shown in figure 3-3 to 3-5 and table 3-2.

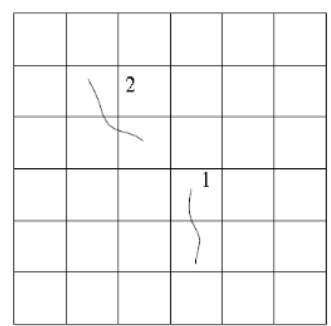

Fig.3-3 SP-1 crack description

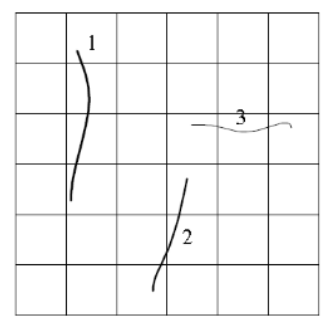

Fig.3-4 SP-2 crack description

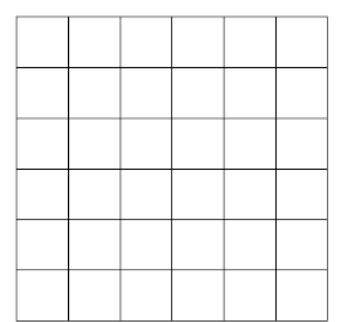

Fig.3-5 SP-3 crack description

Table 3-2 slab cracking grade

\begin{tabular}{lcccc}
\hline mixing & $\begin{array}{l}\text { The average cracks } \\
\text { area (mm2 / root) }\end{array}$ & $\begin{array}{l}\text { The number of cracks } \\
\text { per unit area(root } / \mathrm{m} 2)\end{array}$ & $\begin{array}{c}\text { Total crack area } \\
(\mathrm{mm} 2 / \mathrm{m} 2)\end{array}$ & $\begin{array}{c}\text { Crack resistance } \\
\text { grade }\end{array}$ \\
\hline SP-1 & 17 & 7 & 87 & II \\
SP-2 & 41 & 12 & 94 & III \\
SP-3 & 8 & 3 & 30 & I \\
\hline
\end{tabular}

Crack resistance grade of SP-1 is II, there is a small amount of apparent crack; Crack resistance grade of SP-2 is III, there is some visible cracks; plate cracking grade III; Crack resistance grade of SP-3 is I, there is no obvious cracks.

In conclusion, SP-1 mix ratio has low hydration heat and low adiabatic temperature rise, durability can also meet the requirements, but the intensity margin is relatively low, which is not suitable for the project application; the strength of SP-2 is higher than that of SP-1, but the poor crack resistance grade can not meet the High-strength Mass Concrete Foundation Slab requirements; SP-3 can meet the requirement of the engineering performance in various aspects, such as strength and durability, so we select SP-3 as engineering application mixture ratio.

\section{Summary}

Concrete durability test is through the detection of resistance to chloride ion permeability 、 shrinkage and the slab crack, we select the SP-3 as the engineering application mix ratio finally, the concrete strength and durability all meet the project requirements.

Through thermal calculation, scientific construction and construction method combined with the temperature monitoring of mass concrete ${ }^{[6-7]}$, C60 High-strength Mass Concrete Foundation Slab has realized the temperature target, there is no harmful cracks.

\section{References}

[1] Abifadel Nassim, Johnson Daniel, Evolution of temperature for roller concrete dams[J],Dam Engineering,1992,3:41 46

[2] Jiang Xi-ping, Wang She-liang, Duan Shu-xin. Mechanism analysis of temperature crack appear of super mass concrete and new methods of anti- rack[J].Concrete,2007(12).

[3] Feng Zhong-wei, Li Lin-xiang, Xie Yong-jiang. Experimental research on the shrinkage properties of con crete[J].Concrete,2012(04).

[4] Zhang Ping, Wang Kun, Li Qiu-yi, etc. Experimental research on the early cracking resistance of concrete with high-volume mineral admixture[J].Concrete,2012(01). 
[5] Feng Zhong-wei, Li Lin-xiang, Xie Yong-jiang. Experimental research on the shrinkage properties of con crete[J].Concrete,2012(04).

[6] Pang Erbo, Wang Yan. Numerical simulation and monitoring of temperature field of Gao Yin 117 building[J]. Construction Technology, 2013,(18). (in Chinese)

[7] Zhang Houxian. High rise building construction[M]. Beijing: Peking University Press,2006. (in Chinese) 